\title{
The voluntary food intake by growing pigs of diets containing 'treated' rapeseed meals or extracts of rapeseed meal
}

\author{
By PAULINE A. LEE,* SHARON PITTAM AND R. HILL \\ Department of Animal Husbandry and Hygiene, Royal Veterinary College (University of \\ London), Boltons Park, Potters Bar, Herts.
}

(Received 9 January 1984 - Accepted 24 February 1984)

\begin{abstract}
1. The intake by growing pigs of a diet containing British rapeseed meal (Brsm) extracted once with water was greater than that of a similar diet containing untreated Brsm, and a diet containing Brsm extracted twice with water was eaten more readily than one containing Brsm extracted once with water. Treatment of Brsm with slaked lime increased slightly its acceptability by growing pigs.

2. The addition of a water extract of Brsm to a soya-bean meal ( $\mathrm{Sbm}$ ) diet reduced voluntary intake compared with the voluntary intake of the same Sbm diet with water added. Addition to the diet of a water extract passed through an anion exchange column increased food intake but if a cation exchange column was used there was no effect on intake.

3. Treated rapeseed meals and extracts were analysed for glucosinolates, sinapine and tannins; the results indicated that glucosinolates rather than sinapine or tannin were associated with low feed intake.
\end{abstract}

In a previous report (Lee \& Hill, 1983) it was shown that the intake by growing pigs of diets containing rapeseed meal (Rsm) as the only protein supplement varied with the type or variety of Rsm used. A diet containing meal from autumn sown Brassica napus varieties currently grown in Britain (Brsm) was eaten much less readily than one containing a spring sown Canadian variety, Tower (Trsm). The major identified difference between these rapeseed meals was their glucosinolate content; Brsm contained five to ten times the amount present in Trsm. The object of the present experiments was to examine the possible inverse relationship between glucosinolate content and food intake.

It has been shown that the extraction of Rsm with water removed a very high proportion of the glucosinolates present (Ballester et al. 1970), particularly if hot water was used and the extraction was carried out twice (Eapen et al. 1969). The effect on intake of extracting Brsm with hot water was examined in the present study.

Treating Rsm or crambe seed (Crambe Abyssinica) meal with alkali, either as ammonia (Kirk et al. 1966), sodium carbonate (Mustakas et al. 1968) or calcium hydroxide (Fenwick et al. 1979) has been shown to decompose almost all the sinapine present. The glucosinolates were also decomposed, in part, by $\mathrm{NH}_{3}$ and $\mathrm{Na}_{2} \mathrm{CO}_{3}$. Determination of glucosinolate after lime treatment was not reported but preliminary observations in the present study showed that about half the glucosinolate of Brsm was decomposed by $\mathrm{Ca}(\mathrm{OH})_{2}$; the influence of this treatment on feed intake was determined here to provide evidence of the possible effect of sinapine as well as glucosinolate on intake.

The effects of water extracts of rapeseed meal, either untreated or after having been passed through anion or cation exchange columns, were also examined.

\section{MATERIALS AND METHODS}

Feeding experiments

Expt 1. Growing pigs were used in change-over experiments in the manner described earlier (Lee \& Hill, 1983). There were three parts to the present experiment. In each part the Sbm and Brsm diets (Lee \& Hill, 1983) were compared with a diet containing Brsm after

* Present address: National Institute for Research in Dairying, Shinfield, Reading RG2 9AT. 
treatment: (1) extracted once with water $\left(\mathrm{Brsm} 1 \times 1 \mathrm{H}_{2} \mathrm{O}\right.$ ), (2) extracted twice with water (Brsm $\left.1 \times 2 \mathrm{H}_{2} \mathrm{O}\right)$, (3) treated with $\mathrm{Ca}(\mathrm{OH})_{2}\left(\mathrm{Brsm} 2-\mathrm{Ca}(\mathrm{OH})_{2}\right)$.

Expt 2. Certain details of the change-over design of experiments, but not the underlying basis, were modified for this experiment in which extracts were used. These were necessary to reduce to manageable proportions the time involved in the preparation and treatment of the extracts. In each experimental period, there were four pens of two pigs per pen, with four dietary treatments, and intake was measured on $4 d$, Tuesday to Friday. The pigs were offered the control (soya-bean meal (Sbm)) diet plus water, for $3 \mathrm{~d}$ preceding the experimental period. Within the $4 \mathrm{~d}$ period each pen of pigs was offered each dietary treatment once and all the treatments were given on each day, a similar pattern to that used in previous experiments. To limit the volumes of extracts needed, the experimental diets were given in the morning only; in the afternoon the control diet ( $\mathrm{Sbm}$ ) was given with water. Thus at 09.00 hours one of the experimental diets was given to pigs in each pen and at 16.00 hours the Sbm + water diet was given to all of the pigs. The pigs used were about 8 weeks of age and weighed $18 \mathrm{~kg}$. Water, or the extracts, treated or untreated, were mixed with meal in the proportions 1.5 litres: $1 \mathrm{~kg}$. This was as large a volume of liquid as could be used without a tendency for the liquid to separate on standing. The object was to use a diet that had the maximum possible effect on voluntary food intake. Voluntary food intake was measured by weighing the food remaining $30 \mathrm{~min}$ after the experimental diets were offered.

In the first part of this experiment the Sbm diet + water was compared with the Brsm diet + water, the Sbm diet + untreated Brsm extract (Ext), and the Sbm diet + Brsm extract passed through anion exchange resin (AExt). In the second part, the Sbm diet + water was compared with the Sbm diet + untreated Brsm extract, the Sbm diet + Brsm extract passed through anion exchange resin and the Sbm diet + Brsm extract passed through cation exchange resin (CExt).

\section{Treatments of rapeseed meal and extracts of the meal}

Several different batches of rapeseed meal were used in these experiments but they were all from autumn sown B. napus varieties grown in Britain from 1977 to 1979. It was not possible to obtain meal from specific varieties of seed but almost all the seed produced in the UK during these years was from the variety Jet Neuf. The meals contained high levels of glucosinolates giving on hydrolysis about $10.0 \mathrm{~g}$ oxazolidinethione $/ \mathrm{kg}$ meal.

Water-extracted meal was prepared by adding 9 litres boiling water with $2 \mathrm{~kg}$ meal and mixing for $2 \mathrm{~h}$ in a Hobart mixer. Heat was not applied during mixing. The mixture was then poured into a double thickness of coarse nylon filter bags and the liquid squeezed out with the aid of a wine press. The extracted residue, about $1.3 \mathrm{~kg}$, was dried overnight at $60^{\circ}$ (once-extracted meal), the wet solid was extracted a second time for $2 \mathrm{~h}$ with 5 litres boiling water, squeezed with the wine press and finally dried overnight at $60^{\circ}$ (twiceextracted meal).

$\mathrm{Ca}(\mathrm{OH})_{2}$-treated meal was obtained by first mixing $2 \mathrm{~kg}$ meal with $80 \mathrm{~g} \mathrm{Ca}(\mathrm{OH})_{2}$ in a Hobart mixer for $10 \mathrm{~min}$. While the mixer was still operating 1 litre cold water was added slowly, and mixing was continued until the meal and water were uniformly mixed. The mixture was left to stand for $1 \mathrm{~h}$ at room temperature and then dried in an oven at $50^{\circ}$. About $1.8 \mathrm{~kg}$ of treated meal was obtained per batch, the remainder being lost during transfer from mixer to drying tray.

The water extract used in the feeding experiments was obtained by extracting $2 \mathrm{~kg} \mathrm{Brsm}$ with 7 litres boiling water using the method described previously. The extract was left to stand overnight at $4^{\circ}$ and decanted just before use. Some extract was passed through either an anion or a cation exchange column. Two chromatography glass columns $(1 \mathrm{~m} \times 27 \mathrm{~mm})$ 
were packed with $250 \mathrm{ml}$ Amberlite IRA-410 (CL) anion exchange resin. The aqueous Brsm extract was centrifuged at $500 \mathrm{~g}$ for $10 \mathrm{~min}$ then passed through the columns in series at a flow-rate of $200-250 \mathrm{ml} / \mathrm{h}$. Other aqueous extracts were treated in the same manner but were passed through cation exchange columns containing Amberlite LR-120 sodium-form. The treated extracts were stored overnight at $4^{\circ}$ and used in feeding experiments the following morning.

After a maximum of 2 litres of extract had passed through the columns the resins were washed in deionized water to remove the remaining extract. The resins were then removed from the columns to be regenerated overnight with either $2 \mathrm{M}$-hydrochloric acid for the anion exchange resin or $0.1 \mathrm{M}$-sodium chloride for the cation exchange resin. On repacking, the resins were washed thoroughly by passing approximately 5 litres deionized water through each column. The resins were regenerated a maximum of three times before being discarded.

\section{Analyses of meals and extracts}

Untreated and treated Brsm, and aqueous extracts, (treated and untreated) were analysed for glucosinolates by determining their hydrolysis products. Tannins were determined as tannic acid and sinapine as sinapine bisulphate. The methods were those described in a previous paper (Lee \& Hill, 1983).

\section{Statistical analysis}

Values of food intake, measured as a proportion of the amount offered, were analysed by the variance ratio method.

\section{RESULTS AND DISCUSSION \\ Expt 1. Treated Brsm}

Values of food intake (as a proportion of the amount offered) in Expt 1 are given in Table 1.

The voluntary intake of the diet containing once-extracted meal $\left(\mathrm{Brsm} 1 \times 1 \mathrm{H}_{2} \mathrm{O}\right), 0.63$, was significantly less $(P<0.001)$ than that of the Sbm diet $(0.86)$ but was also significantly greater than that of the untreated Brsm diet $(0 \cdot 46)$. The twice-extracted meal was eaten even more readily and intake was not significantly less than that of the Sbm diet. Intake of the

Table 1. Expt 1. The voluntary feed intake during the first 30 min after morning and afternoon feeds by growing pigs given diets containing soya-bean meal $(\mathrm{Sbm})$ or treated or untreated rapeseed meal (Brsm) measured as a proportion of the amount of feed offered

\begin{tabular}{|c|c|c|c|c|c|c|}
\hline \multirow[b]{2}{*}{ Treatment } & \multirow[b]{2}{*}{$\begin{array}{l}\text { No. of values } \\
\text { per treatment }\end{array}$} & \multicolumn{3}{|c|}{ Diets* } & \multirow[b]{2}{*}{ SED } & \multirow{2}{*}{$\begin{array}{c}\text { Statistical } \\
\text { significance } \\
\text { of difference } \\
\text { between means: } P\end{array}$} \\
\hline & & Sbm & Brsm & $\begin{array}{c}\text { Treated } \\
\text { Brsm }\end{array}$ & & \\
\hline $\begin{array}{l}\text { (1) Extracted once } \\
\text { with water }\end{array}$ & 30 & 0.86 & 0.46 & 0.63 & 0.058 & $<0.001$ \\
\hline $\begin{array}{l}\text { (2) Extracted twice } \\
\text { with water }\end{array}$ & 12 & 0.87 & 0.34 & 0.78 & 0.061 & $<0.001$ \\
\hline $\begin{array}{l}\text { (3) Treated with } \\
\text { calcium hydroxide }\end{array}$ & 36 & 0.97 & 0.62 & 0.73 & 0.037 & $<0.001$ \\
\hline
\end{tabular}

SED, standard error of difference.

* Details of the basal diets are given in Lee \& Hill (1983). 
Table 2. Oxazolidinethione, isothiocyanate, sinapine bisulphate and tannic acid equivalent content $(\mathrm{g} / \mathrm{kg})$ of rapeseed meal (Brsm 1; Brsm 2); Brsm l extracted once $\left(\mathrm{Brsm} \mathrm{I} \times \mathrm{IH}_{2} \mathrm{O}\right)$ or twice $\left(\mathrm{Brsm} \mathrm{I} \times 2 \mathrm{H}_{2} \mathrm{O}\right)$ with hot water and Brsm 2 treated with calcium hydroxide $\left(\mathrm{Brsm} 2-\mathrm{Ca}(\mathrm{OH})_{2}\right)$

\begin{tabular}{|c|c|c|c|c|}
\hline \multirow[b]{2}{*}{ Rapeseed meals } & \multicolumn{2}{|c|}{ Hydrolysis products of glucosinolates } & \multirow{2}{*}{$\begin{array}{c}\text { Sinapine } \\
\text { bisulphate }\end{array}$} & \multirow{2}{*}{$\begin{array}{l}\text { Tannic acid } \\
\text { equivalent }\end{array}$} \\
\hline & Oxazolidinethione & Isothiocyanate & & \\
\hline Brsm 1 & $10 \cdot 7$ & 1.08 & $10 \cdot 3$ & $17 \cdot 5$ \\
\hline Brsm $1 \times 1 \mathrm{H}_{2} \mathrm{O}$ & $5 \cdot 0$ & 0.72 & $4 \cdot 9$ & $17 \cdot 7$ \\
\hline Brsm $\mathrm{I} \times 2 \mathrm{H}_{2} \mathrm{O}$ & $2 \cdot 3$ & 0.47 & 0.6 & $15 \cdot 2$ \\
\hline Brsm 2 & $10 \cdot 5$ & $0 \cdot 40$ & $11 \cdot 3$ & $15 \cdot 3$ \\
\hline $\operatorname{Brsm} 2-\mathrm{Ca}(\mathrm{OH})_{2}$ & $8 \cdot 4$ & $0 \cdot 31$ & $2 \cdot 4$ & $14 \cdot 0$ \\
\hline
\end{tabular}

diet containing twice-extracted meal $\left(\mathrm{Brsm} 1 \times 2 \mathrm{H}_{2} \mathrm{O}\right), 0 \cdot 78$, was much greater than that of the corresponding untreated Brsm diet, 0.34 , and the difference was highly significant $(P<0.001)$. Treating the meal with $\mathrm{Ca}(\mathrm{OH})_{2}$ significantly improved the palatability but the intake of this diet $\left(\mathrm{Brsm} 2-\mathrm{Ca}(\mathrm{OH})_{2}\right), 0 \cdot 73$, was still much lower than that of the Sbm diet, 0.97 , and this difference was highly significant $(P<0.001)$.

The results of analyses of the treated and untreated Brsm are given in Table 2.

The glucosinolate contents, determined as their hydrolysis products, and the sinapine and tannic acid contents of the untreated meals, were similar to those of Brsm used in earlier experiments (Lee \& Hill, 1983). Extraction twice with hot water (Brsm $1 \times 2 \mathrm{H}_{2} \mathrm{O}$ ) removed about 0.75 of the total glucosinolates, 0.95 of the sinapine and $0.07-0.10$ of the tannins. Treatment with $\mathrm{Ca}(\mathrm{OH})_{2}\left(\mathrm{Brsm} 2-\mathrm{Ca}(\mathrm{OH})_{2}\right)$ produced a large reduction $(0 \cdot 8)$ in the sinapine content of the meal, but it reduced the glucosinolate and tannin levels by only about 0.2 and $0 \cdot 1$ respectively. These results, when considered alongside food intake values given in Table 1, which show a substantially greater improvement with meal extracted twice with water than with meal treated with $\mathrm{Ca}(\mathrm{OH})_{2}$, give weight to the proposal that the glucosinolates, rather than sinapine or tannins, reduced feed intake.

\section{Expt 2. Extracts of rapeseed meal}

Values of food intake (as a proportion of the amount offered) in Expt 2 are given in Table 3.

There was a marked and highly significant $(P<0.001)$ difference between the intakes of the Sbm and Brsm diets with water added. Addition of Ext to the Sbm diet in place of water decreased the intake significantly whilst addition of AExt produced only a slight decrease in intake which did not approach significance.

In the second part of the experiment, intakes of the Sbm diet with the addition of Ext and AExt followed the same pattern as seen in the first part of the experiment. Addition of CExt to the Sbm diet significantly $(P<0.001)$ depressed intake, the value being not significantly different from that for the Sbm diet plus Ext. Thus AExt had no adverse effect on intake while the CExt depressed intake to the same extent as the Ext.

The results of analyses carried out on the extracts of rapeseed meal are given in Table 4 .

Passage through the anion exchange resin (AExt) removed almost all the glucosinolates, determined here as the hydrolysis products oxazolidinethione and isothiocyanates, none of the sinapine and about one-third of the tannins, whereas passage through the cation exchange resin (CExt) had little effect on the glucosinolates but removed almost all of the sinapine and about one-third of the tannins. As the extract after treatment with anion resin 
Table 3. Expt 2. The voluntary feed intake during the first 30 min after the morning feed by young pigs given diets containing water, or untreated (Ext) or treated (anion exchange, AExt; cation exchange, CExt) aqueous extracts of British rapeseed meal (Brsm)

\begin{tabular}{|c|c|c|c|c|c|c|c|}
\hline \multirow{2}{*}{$\begin{array}{l}\text { No. of } \\
\text { values per } \\
\text { treatment }\end{array}$} & \multicolumn{4}{|c|}{ Sbm diet* } & \multirow{2}{*}{$\begin{array}{l}\text { Brsm } \\
\text { diet }+ \\
\text { water }\end{array}$} & \multirow[b]{2}{*}{ SED } & \multirow{2}{*}{$\begin{array}{c}\text { Statistical } \\
\text { significance } \\
\text { of difference } \\
\text { between means: } P\end{array}$} \\
\hline & +water & $+E x t$ & + AExt & $+\mathrm{CExt}$ & & & \\
\hline 20 & 0.86 & 0.32 & 0.74 & - & $0 \cdot 30$ & 0.084 & $<0.001$ \\
\hline 12 & 0.95 & 0.43 & 0.97 & 0.46 & - & 0.057 & $<0.001$ \\
\hline
\end{tabular}

Sbm, soya-bean meal; SED, standard error of difference.

* Details of the basal diet are given in Lee \& Hill (1983).

Table 4. Oxazolidinethione, isothiocyanate, sinapine bisulphate and tannic acid equivalent contents $(\mathrm{g} / \mathrm{l})$ of treated and untreated aqueous extracts of British rapeseed meal

\begin{tabular}{ccccc}
\hline \hline & \multicolumn{1}{c}{ Hydrolysis products of glucosinolates } & & \\
\cline { 2 - 3 } Extract & Oxazolidinethione & Isothiocyanate & $\begin{array}{c}\text { Sinapine } \\
\text { bisulphate }\end{array}$ & $\begin{array}{c}\text { Tannic acid } \\
\text { equivalent }\end{array}$ \\
\hline $\begin{array}{c}\text { Untreated } \\
\text { Extract passed } \\
\text { through anion } \\
\text { exchange resin } \\
\text { Extract passed } \\
\text { through cation } \\
\text { exchange resin }\end{array}$ & 3.14 & 0.154 & 1.87 & 4.80 \\
\hline \hline
\end{tabular}

did not depress intake and the extract after treatment with cation resin did depress intake, it is evident that sinapine had no effect on intake, tannins probably had very little effect and the glucosinolates had a substantial depressing effect.

In part 1 of Expt 2 (Table 3) there was not a direct relation between the amount of glucosinolate present in the diet and the depression of food intake. It can be calculated from the glucosinolate content of Brsm (Table 2), the composition of the Brsm diet (Lee \& Hill, 1983) and the glucosinolate content of the Ext (Table 4) that the glucosinolate content of the treatment 'Sbm + Ext' was almost twice that of the treatment 'Brsm + water', while the depression in food intake was similar in each case. This may indicate that the reduction of food intake with the 'Brsm + water' diet was close to the maximum given by glucosinolate in these particular circumstances or that the effect per unit weight of glucosinolate was greater when present as an integral part of a food than when added in solution. It is also possible that substances other than glucosinolates, that were not extracted, contributed to the depression of food intake.

The results described here and in a previous paper (Lee \& Hill, 1983) provide strong evidence that the major fraction of rapeseed meal causing reduced voluntary feed intake in growing pigs was the glucosinolates and if other substances contributed to this effect they did not include sinapine and probably not tannins.

The authors thank Dr J. A. Stedman for providing the sinapine values quoted and the Agricultural and Food Research Council for financial support. 


\section{REFERENCES}

Ballester, D., Rodrigo, R., Nakouzi, J., Chichester, C. O., Yán̄ez, E. \& Mönckeberg, F. (1970). Journal of the Science of Food and Agriculture 21, 143-144.

Eapen, K. E., Tape, N. W. \& Sims, R. P. A. (1969). Journal of the American Oil Chemists' Society 46, 52-55.

Fenwick, G. R., Hobson-Frohock, A., Land, D. G. \& Curtis, R. F. (1979). British Poultry Science 20, $323-329$.

Kirk, L. D., Mustakas, G. C. \& Griffin, E. L. Jr. (1966). Journal of the American Oil Chemists' Society 43(ii), 550-555.

Lee, P. A. \& Hill, R. (1983). British Journal of Nutrition 50, 661-671.

Mustakas, G. C., Kirk, L. D., Griffin, E. L. Jr. \& Clanton, D. C. (1968). Journal of the American Oil Chemists' Society 45, 53-57. 